\title{
Examining the dynamics between young people's mental health, poverty and life chances in six low- and middle-income countries: protocol for the CHANCES-6 study
}

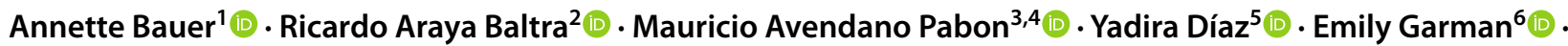

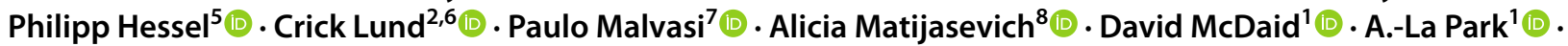

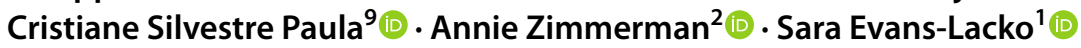

Received: 8 April 2020 / Accepted: 29 January 2021 / Published online: 19 July 2021

(C) The Author(s) 2021

\begin{abstract}
Purpose Poverty and poor mental health are closely related and may need to be addressed together to improve the life chances of young people. There is currently little evidence about the impact of poverty-reduction interventions, such as cash transfer programmes, on improved youth mental health and life chances. The aim of the study (CHANCES-6) is to understand the impact and mechanisms of such programmes.

Methods CHANCES-6 will employ a combination of quantitative, qualitative and economic analyses. Secondary analyses of longitudinal datasets will be conducted in six low- and middle-income countries (Brazil, Colombia, Liberia, Malawi, Mexico and South Africa) to examine the impact of cash transfer programmes on mental health, and the mechanisms leading to improved life chances for young people living in poverty. Qualitative interviews and focus groups (conducted among a subset of three countries) will explore the views and experiences of young people, families and professionals with regard to poverty, mental health, life chances, and cash transfer programmes. Decision-analytic modelling will examine the potential economic case and return-on-investment from programmes. We will involve stakeholders and young people to increase the relevance of findings to national policies and practice.

Results Knowledge will be generated on the potential role of cash transfer programmes in breaking the cycle between poor mental health and poverty for young people, to improve their life chances.

Conclusion CHANCES-6 seeks to inform decisions regarding the future design and the merits of investing in povertyreduction interventions alongside investments into the mental health of young people.
\end{abstract}

Keywords Young people $\cdot$ Mental health $\cdot$ Poverty $\cdot$ Life chances $\cdot$ Cash transfer programme $\cdot$ Mixed-method study

Sara Evans-Lacko

s.evans-lacko@1se.ac.uk

1 Department of Health Policy, Care Policy and Evaluation Centre, London School of Economics and Political Science, London, UK

2 Centre for Global Mental Health, Health Service \& Population Research Department, Institute of Psychiatry, Psychology and Neuroscience, King's College London, London, UK

3 Department of Global Health \& Social Medicine, Institute of Psychiatry, Psychology and Neuroscience, King's College London, London, UK

4 Department of Social and Behavioural Sciences, Harvard School of Public Health, Boston, USA
5 Escuela de Gobierno Alberto Lleras Camargo, Universidad de Los Andes, Bogotá, Colombia

6 Department of Psychiatry and Mental Health, Alan J Flisher Centre for Public Mental Health, University of Cape Town, Cape Town, South Africa

7 Faculdade de Ciências Médicas da Santa Casa de São Paulo, Department of Public Health, Universidade de São Paulo, São Paulo, Brazil

8 Faculdade de Medicina FMUSP, Departamento de Medicina Preventiva, Universidade de São Paulo, São Paulo, Brazil

9 Programa de Pós-Graduação em Distúrbios do Desenvolvimento, Universidade Presbiteriana Mackenzie, São Paulo, Brazil 


\section{Background}

\section{Mental health, poverty and life chances}

Globally, one in four people are aged between 10 and 24 years, making up 1.8 billion of today's world population [1]. Ninety percent of these young people live in low- and middle-income countries (LMICs) [2]. In LMICs, 20\% live on less than $\$ 1.90$ a day corresponding to about 385 million individuals [3]. Young people living in poverty face multiple forms of cumulative disadvantage-such as violence, crime, lack of educational or employment opportunities-which can significantly limit their future life chances and put them at higher risk of mental disorders [4-6]. Life chances are commonly regarded as a combination of factors that determine a young person's opportunity to improve their quality of life [7], and have influenced current debates on child poverty and social mobility $[6,8,9]$.

The nature of the relationship between poverty and mental health has been subject to academic research for decades [10]. Theories of social causation and social drift have been developed [11, 12] and-to some extent-empirically tested [13] to explain bi-directional links. The social causation theory describes how poverty leads to mental health problems by increasing exposure to violence and trauma or reducing access to social capital. Conversely, the social drift theory hypothesises that mental health problems lead to poverty because they can increase healthcare expenditure, risk of stigma, social exclusion, and loss of employment $[11,13]$. Taken together, this relationship leads to a vicious cycle that makes it difficult for individuals to escape poverty and improve mental health. However, it is now widely understood that poverty is a complex multidimensional concept $[14,15]$ and the nature and strength of the relationship between mental health and poverty also depends on how poverty is conceptualised, measured and experienced [10].

Until now, research on poverty and mental health has focused predominantly on adult populations, and little is known about how the relationship applies to youth [16]. Yet, most mental disorders emerge during adolescence $[17,18]$. Mental disorders are the leading contributor to the global disease burden for those aged 10-24 years, with self-harm and violence being the fourth [19]. Whilst mental health problems affect 10-20 per cent of children and young people worldwide [20], the burden is not equally distributed across socio-economic groups [21, 22]. It is estimated that those living in the poorest fifth of the population are twice as likely to develop mental health problems compared to those with average incomes [23].

\section{Interventions}

Adolescence is an important time to intervene to prevent mental health problems and poverty in adulthood [24]. Because these outcomes are linked to lifetime losses in employment, other productive activities and health-related quality of life, it has been argued that even if interventions were only able to modestly reduce the incidence or severity of symptoms, their return-on-investment could be substantial [25]. Both anti-poverty programmes and mental health interventions might offer opportunities to break the cycle of poverty and mental illness [26, 27].

There is emerging evidence for promotion, prevention and treatment interventions for mental health among young people in LMICs. Interventions that promote positive mental health can be implemented successfully in school or community settings in LMICs [28]. Mental health treatments have been shown to not only reduce mental health symptoms but also help people stay in or regain employment [27, 29-31]. Overall, there is little synthesised evidence of the full range of mental health interventions for young people living in poverty, and the types of short- and long-term economic outcomes they achieve [13, 32]. However, the need for interventions to address social determinants of mental health problems, including poverty, in LMIC settings is widely recognised $[33,34]$. This includes social protection measures, such as cash transfer programmes (CTPs), which have been used to target young people in some countries, and which arguably have a role in improving their mental health whilst reducing poverty [35].

CTPs provide regular direct cash payments to individuals or families identified as living in poverty. Some enforce conditions that individuals need to adhere receive the payment, such as regular health checks or school attendance. In some countries, CTPs are the main vehicle for supporting people living in poverty. During the COVID-19 pandemic, they have been used to reach out to people previously not covered or extend payments to existing beneficiaries to provide a basic safety net for those atrisk of losing their livelihoods [35]. Although evidence is only emerging, CTPs have shown that they improve mental health, for example by reducing suicide rates among adults [36-38]. Among young people, evidence suggests that they can reduce depressive symptoms and psychological distress [16, 26, 39]. Evidence of the effects of CTPs is strongly context specific with outcomes depending on population characteristics as well as programme features [27, 40-43]. For example, they can depend on 
the amount, regularity and duration of payments [42, 44]. Programme conditionalities, and the way they are administered can also negatively impact young people's mental health, especially when those are difficult to achieve for the young person, and when an important proportion of family income depends on it [45]. So far, the vast majority of programmes have not intentionally planned for such effects in their design. An exception to this is the Colombian 'Jóvenes en Acción' ('Youth in Action'), which offers direct monthly payments to young people for attending and completing education programmes, and incorporates mental health promotion elements such as interpersonal skills building and emotional regulation. Whilst its impact on mental health has not yet been assessed, findings from its evaluation suggest that it can effectively improve their chances of entering formal employment [46], which is a likely contributor to improved long-term mental health.

Overall, important evidence gaps remain that prevent programme funders and designers from making decisions about allocating resources so that they contribute to breaking the cycle between poverty and poor mental health for young people, and improve their long-term outcomes. In particular, there is limited knowledge in regards to the impact of CTPs on youth mental health, and the mechanisms-such as programme features, population characteristics or contextual factors-at play [27, 40-43]. Whilst there is evidence of the adverse impact of children's mental health problems on their life chances, including those related to future (mental) health, education, skills, engagement in the labour force, social function in terms of partnership, family formation and citizenship [5], this knowledge is largely from high income countries. Furthermore, while there have been some economic evaluations of the educational impact of CTPs [47], evidence on their cost-effectiveness for health outcomes is largely absent.

Based on the summarised evidence and evidence gaps, we hypothesise that CTPs can improve youth mental health and that mental health is an important factor on the path to improved life chances. Furthermore, we hypothesise that programme features and design alter mental health and life chances outcomes, and hence influence the cost-effectiveness of programmes.

\section{Aims and objectives}

The goal of CHANCES- 6 is to advance current understanding of the dynamics between poverty, mental health and life chances in young people. We will do this by examining both the impact of poverty reduction policies on mental health, and the economic impact of mental health interventions on life chances and future risk of poverty. Findings will be used to inform decisions regarding the merits of investing in and future design of CTPs alongside investments into the mental health of young people in LMICs.

Running from September 2018 to November 2021, the project is funded by the United Kingdom's (UK's) Economic and Social Research Council and led by the Care Policy and Evaluation Centre at the London School of Economics and Political Science. It has partners in the UK (King's College London) and three LMICs: Brazil (Universidade Presbiteriana Mackenzie), Colombia (Universidad de los Andes) and South Africa (University of Cape Town). Quantitative data analyses cover an additional three Latin American and African countries: Liberia, Mexico and Malawi.

CHANCES- 6 seeks to address the following objectives:

- To understand the impact of CTPs, and their specific components (e.g., conditionality, age at first receipt and length of receipt) on young people's mental health and on outcomes in early adulthood that predict life chances (objective 1);

- To understand the mechanisms and pathways from mental health and poverty to improved life chances; this includes understanding the relationship between poverty and mental health, and the extent to which improvements in mental health mediate or moderate the relationship between CTPs and life chances (objective 2);

- To investigate the economic impact of CTPs (with and without a mental health component) (objective 3);

- To understand the perspectives of professional groups involved in funding or running programmes, as well as the views and experiences of young people and their families who participate in CTPs; this includes understanding barriers in current provisions and opportunities for improving programmes (objective 4).

An overarching goal of CHANCES-6 is to inform policies and programmes. Thus, an additional study objective is:

- To engage with stakeholders and young people to ensure that the knowledge is relevant to them and can inform national policies and the design and implementation of local programmes (Objective 5).

\section{About the countries and their CTPs}

In each of the six countries, one or several large datasets exist that are longitudinal in nature, measure the receipt of CTPs and include relevant mental health and life chances outcomes (Table 1). In Brazil, Colombia, South Africa and Mexico, CTPs refer to national programmes, whilst in Malawi and Liberia, the CTPs were introduced as part of experimental studies. Programmes in Colombia and Mexico 


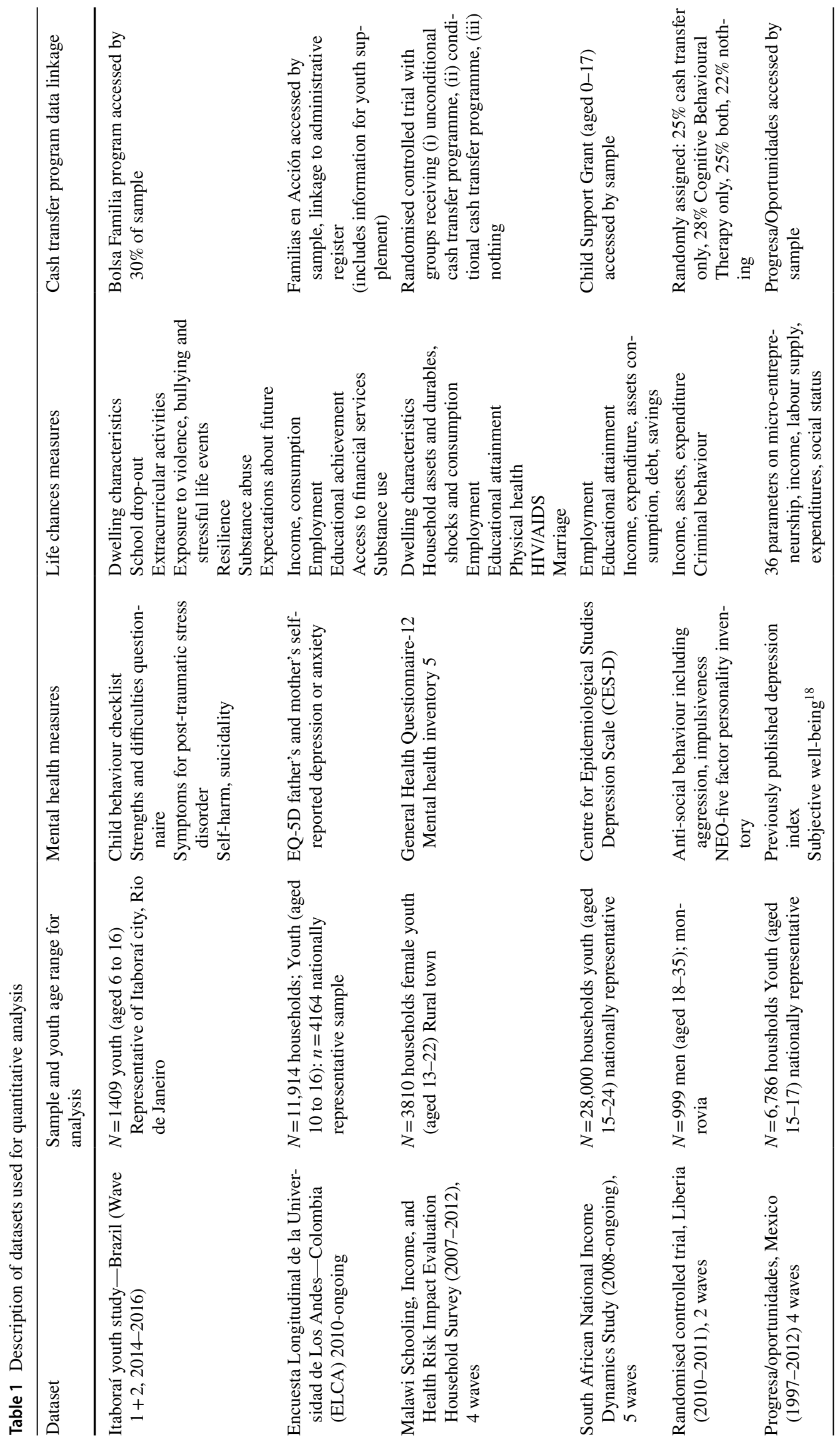




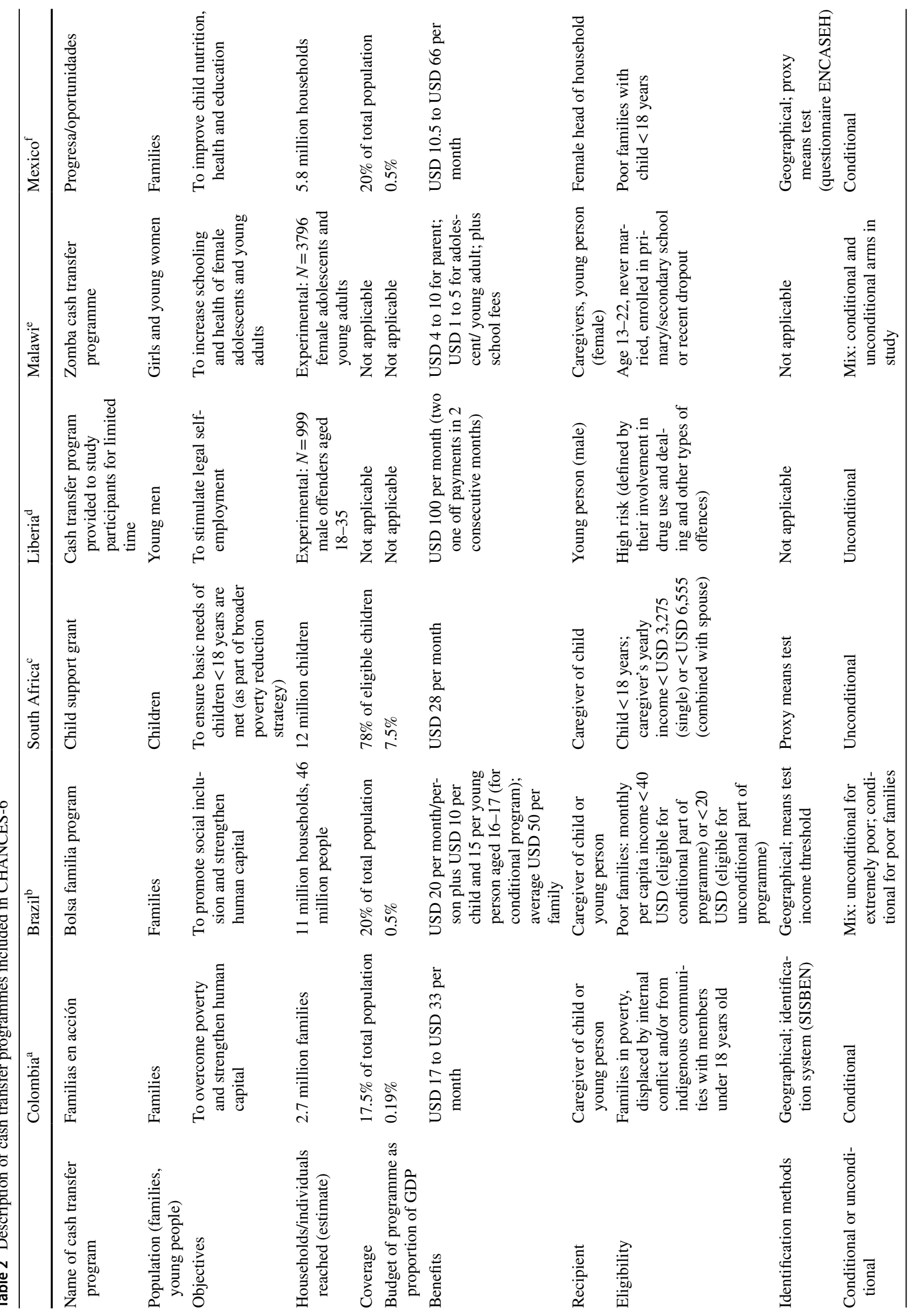




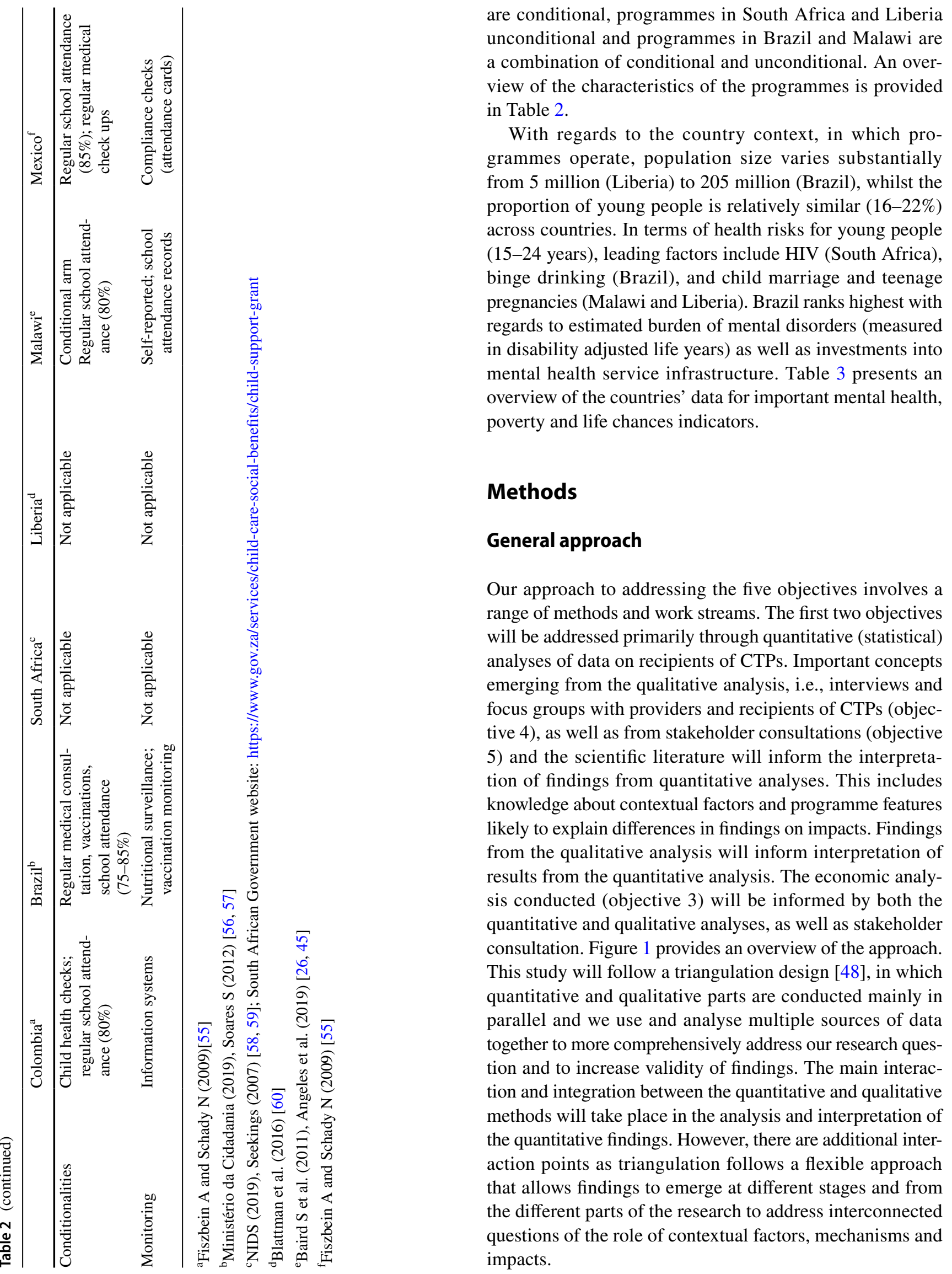




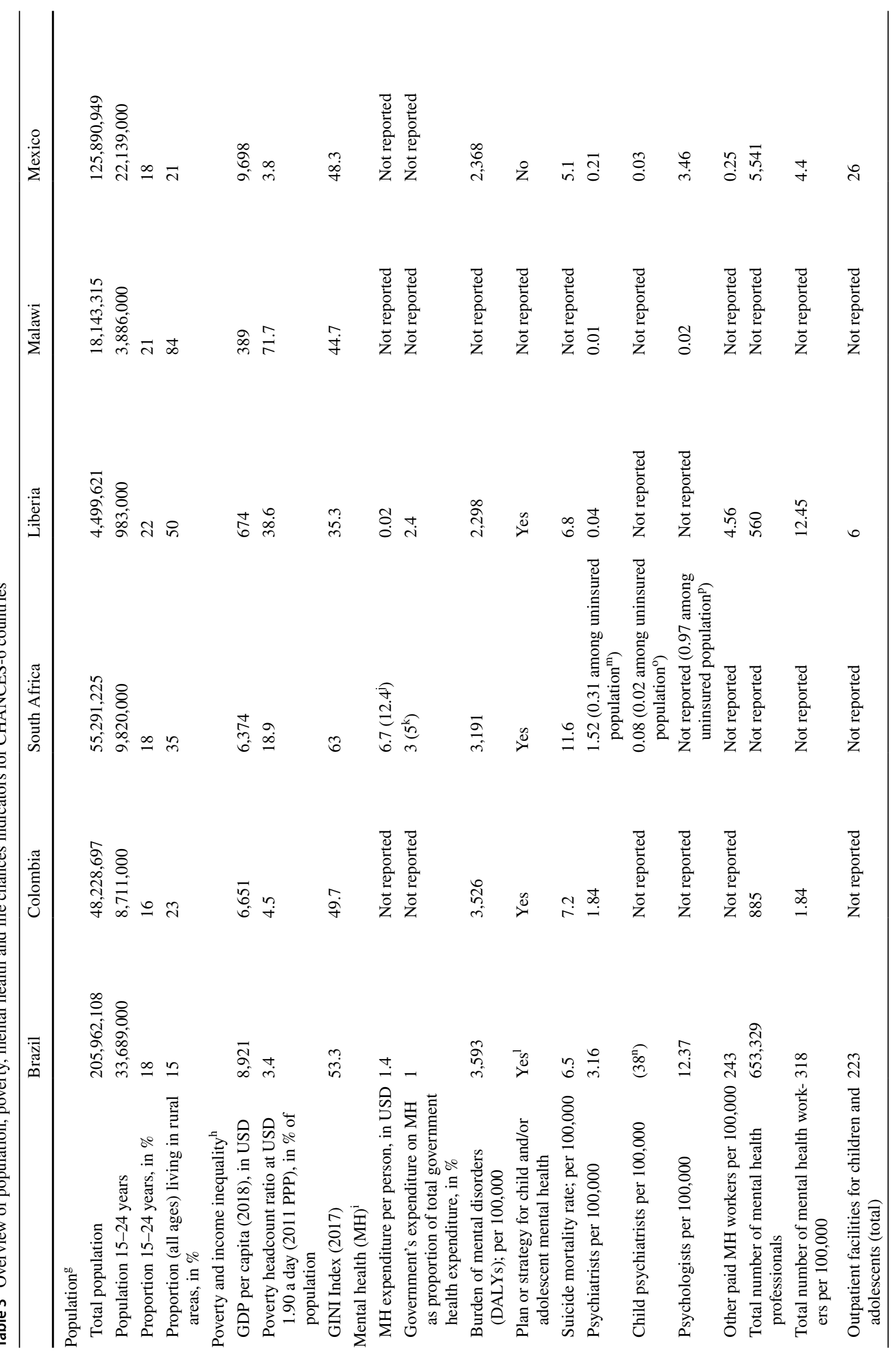




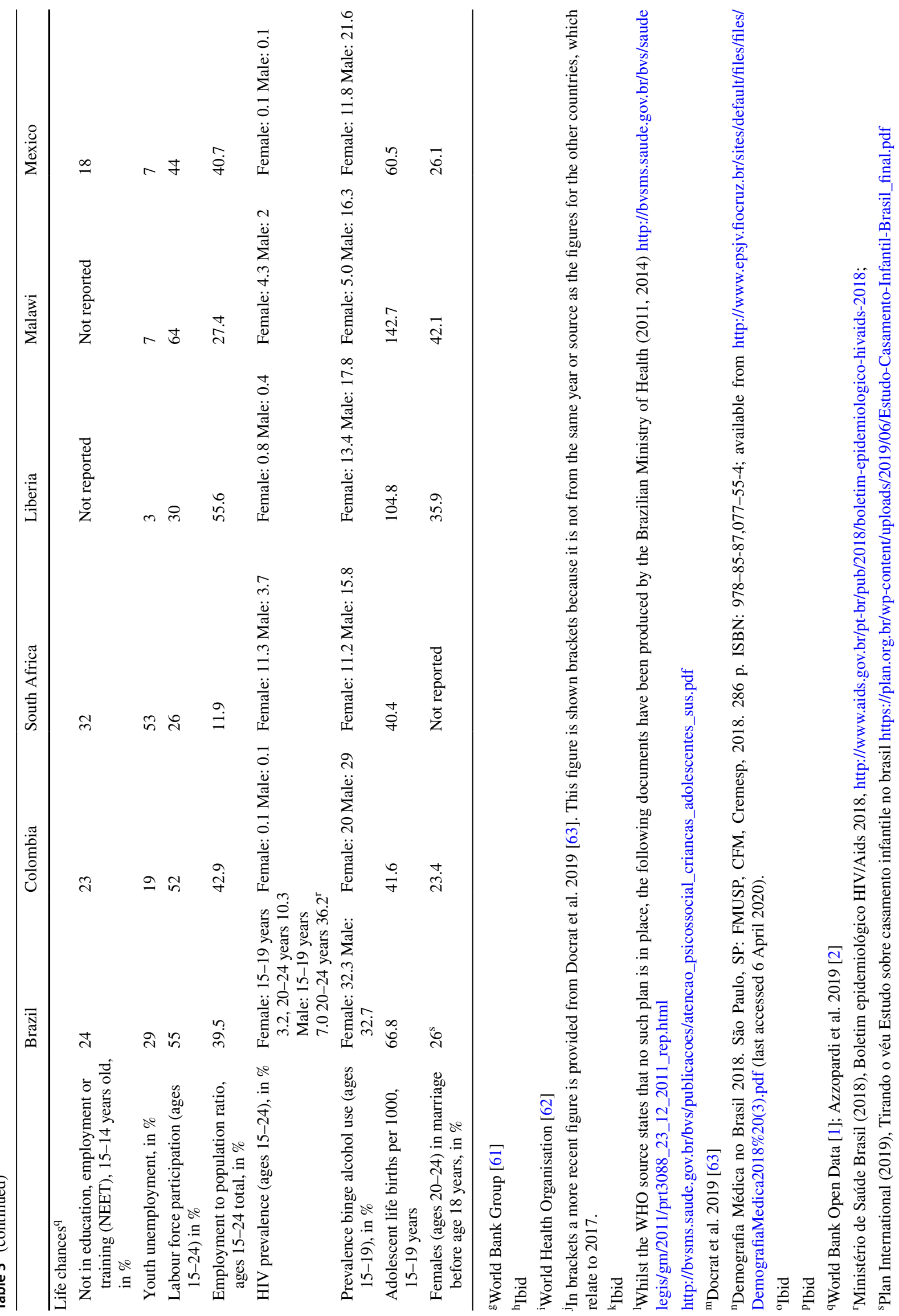


Fig. 1 Overview of the general approach

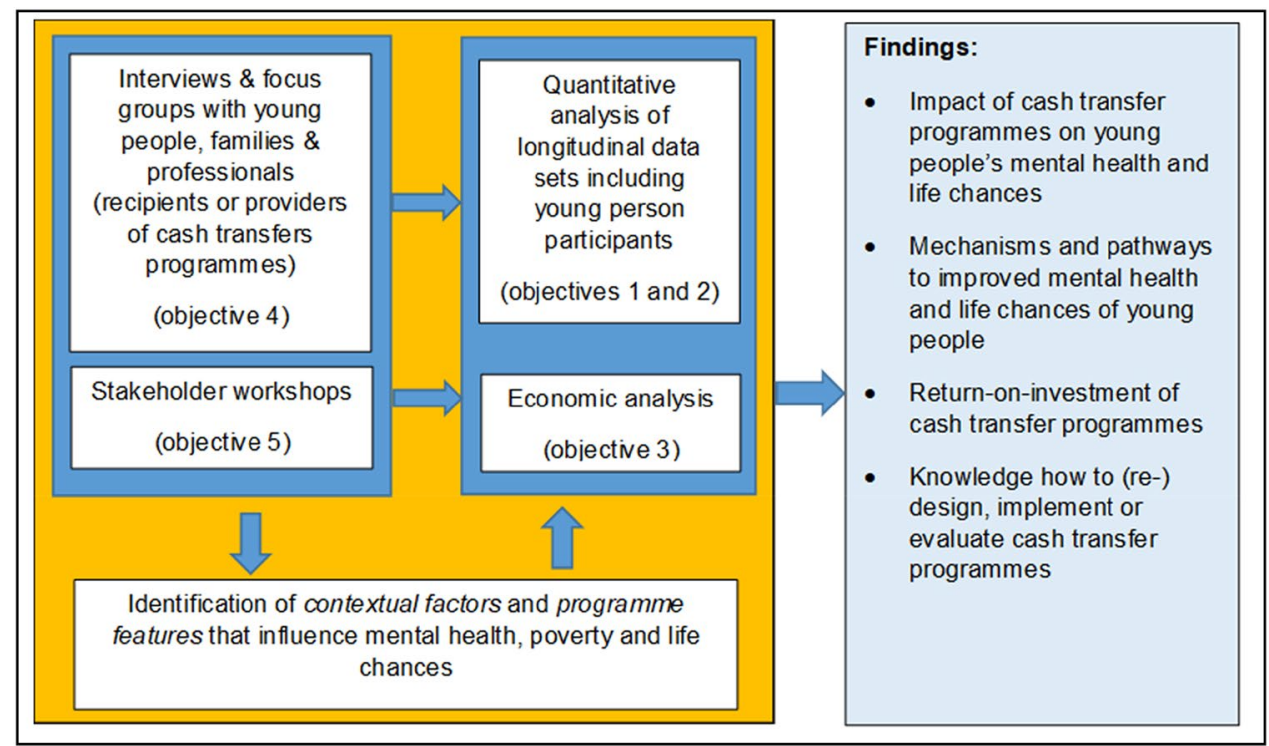

\section{Investigating the impact of CTPs (Objective 1)}

In quantitative (statistical) analyses, we will explore effects of the CTPs on mental health and on life chances outcomes by first examining impacts overall and then by mental health status, adjusting for all relevant covariates. We will first conduct country-specific analysis on each CTP, and then conduct analysis based on data that are harmonised across all countries. The primary data sources for the quantitative analysis will be data from intervention and population panel studies in each of the six countries (Table 1). Table 4 presents the socio-demographic characteristics of young people and their households from the population panel studies in Brazilian, Colombian and South African, including a comparison of characteristics of young people with and without mental health problems.

All studies have used validated measures of poverty, mental health and life chances variables from well-established datasets. Based on these secondary datasets, we will investigate the impact of CTPs on mental health, and on life chances variables for young people. Different age ranges will be considered depending on eligibility criteria for the CTP and study design (Table 1). As much as this is possible mental health variables that indicate conditions will be analysed on a continuum "from mild, time-limited distress to chronic, progressive and severely disabling conditions" [18]. In addition to assessing mental health conditions, variables which focus on related positive aspects of mental health such as life satisfaction, selfesteem, self-efficacy, and resilience will be analysed. With regard to life chances, a range of variables are measured in studies that provide indicators of the present situation and future of young person participants. These include educational achievements, employment status, income, substance misuse, living arrangements and relationship status (Table 1). In terms of poverty, relevant variables exist in each of the datasets, which allows us to adopt a multi-dimensional approach to poverty.

Our data analysis strategies will be based on quasi-experimental evaluation techniques [49] and other epidemiological approaches. As examples of quasi-experimental techniques we will identify so-called 'discontinuities' in the eligibility criteria for CTPs (often based, in parts, on an income or poverty threshold) and use a regression discontinuity design [8]. For some programmes, we will use a difference-in-differences design, incorporating propensity score matching when appropriate. As for other epidemiological approaches, we will use different ways of estimating associations and causal effects of programs with cross-sectional and longitudinal data. The analytic method will be selected based on: (a) presence (or not) of necessary information/variables as well as number of observations for applying each quasiexperimental method and (b) verification of main identification assumptions underlying each method. Where the data meet the criteria of more than one method, we will compare results of all available methods.

Data harmonisation will include identifying commonalities and differences in mental health, life chances and poverty measures, and harmonising them across datasets, for example, using standardised percentile scores. Since datasets refer to different time periods, collected at different waves, and covering different age ranges, a selection will be made for the harmonised dataset, choosing data for time periods and age ranges most closely aligned with each other. The harmonisation process will involve collating shared variables (regarding the CTPs, mental health, life chances, poverty and socioeconomic status) and using the differences between programmes to answer 


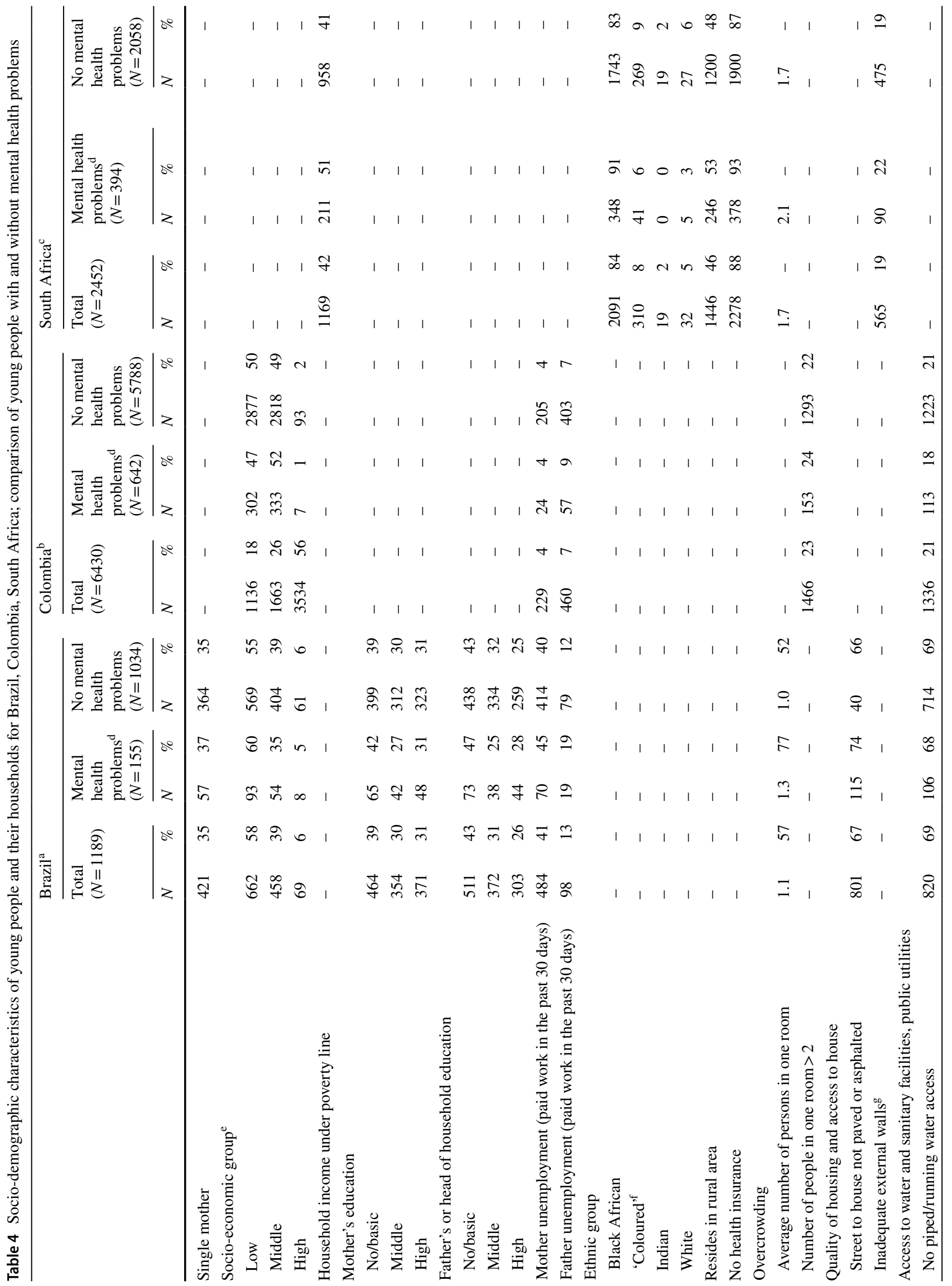




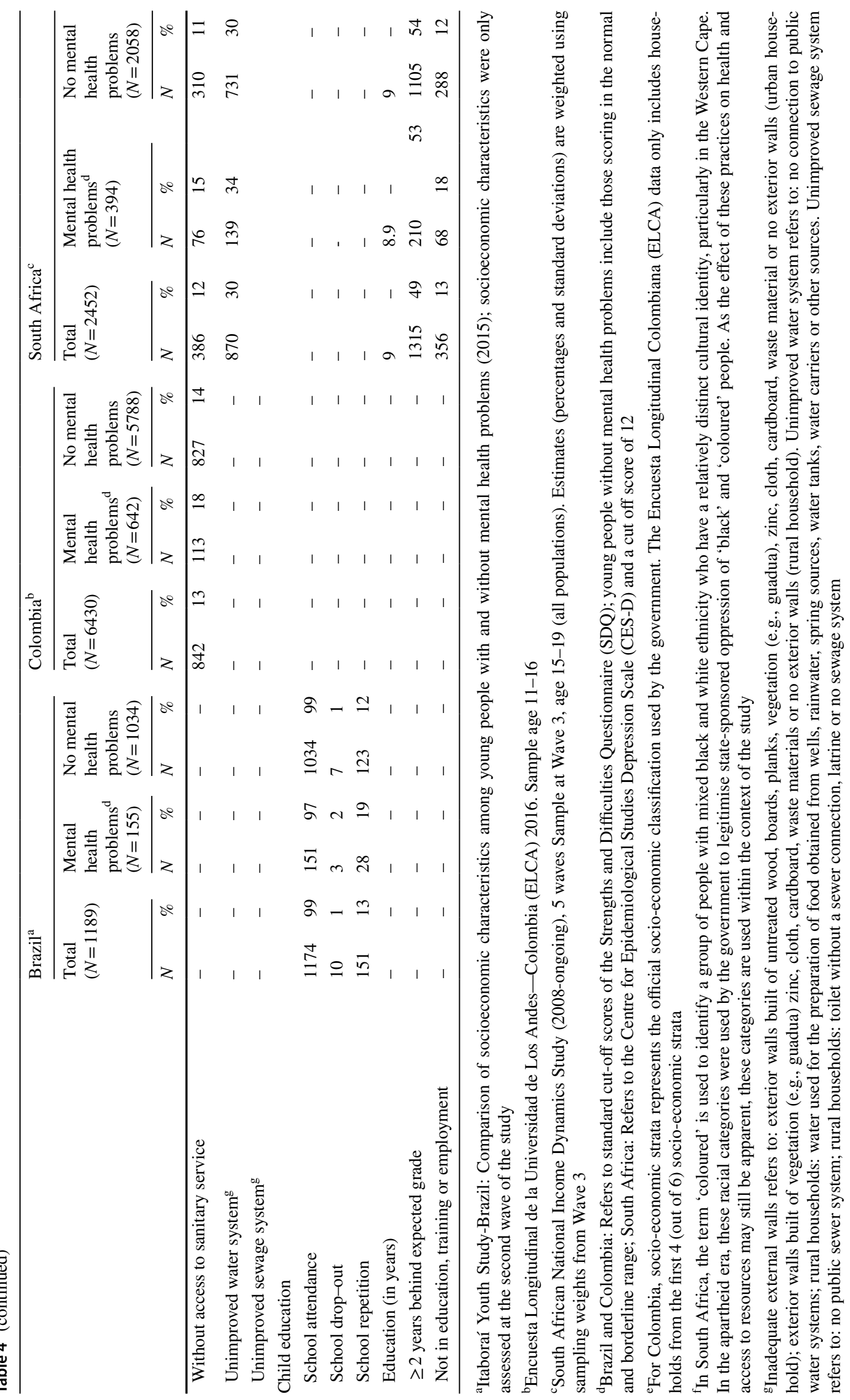


key questions about their effect on mental health. This will allow comparisons across cultures and across CTPs (e.g., conditionality, age at receipt, length of receipt) to determine which features of the CTP are associated with better improvements in mental health and life chances. Online resource 2 provides an example of how data might be harmonised, by demonstrating this for selected datasets and indicators.

\section{Delineating pathways and identifying mechanisms (Objective 2)}

We will conceptualise and assess pathways that explain relationships between poverty, mental health and future life chances, and the influence CTPs have on them. This will be done primarily using quantitative analyses of datasets mentioned above (Table 1). As with the analysis of impact, parameters will be informed by qualitative findings, as well as scientific literature and stakeholder consultation. In addition, qualitative data could provide a broader conceptualisation of pathways and mechanisms, including those that cannot be tested quantitatively through our analyses (but that might inform future data collection and analyses).

First, we will carry out a systematic review of the literature on the impact of CTPs on mental health outcomes of young people, focusing on LMICs. We will then develop a conceptual framework of hypothesised pathways and mechanisms based on those contextual factors, conditionalities and features of CTPs identified as important in previous evaluations of CTPs and mental health programmes, other relevant scientific literature and views and experiences from young people and professionals involved in or knowledgeable of CTPs.

Overlaps between data gathered from the reviewed literature and our own knowledge (including knowledge based on data collected by that time) will be used to confirm the importance of pathways. Where data from different sources diverge, this will be also highlighted.

Next, where possible, we will test some of the mechanisms linking mental health and poverty to improved life chances. Potential variables to consider as having a role in those pathways include:

- Contextual factors: e.g., unemployment, social cohesion, family functioning;

- Conditionalities: e.g., school attendance and child health visits; and

- Other programme features: e.g., amount of money; length of time receiving the cash transfer; ways of monitoring compliance
We will develop statistical models using recommended methods for mediation and moderation [50]. For example, we will examine whether CTPs are associated with improvements in mental health and if these improvements mediate any improvement in future life chances.

\section{Simulating cost-effectiveness of CTPs and mental health interventions (Objective 3 )}

Decision analytical modelling will be conducted to estimate the return-on-investment to the public purse from investing in country specific CTPs given any potential association we identify with mental health outcomes and life chances. This will be compared with expected outcomes and public purse costs associated with no intervention. In addition, the return-on-investment from investing in CTPs will be compared with alternative or complementary investment in selected effective mental health interventions in LMIC contexts. Such interventions will be identified in published systematic reviews and meta-analyses.

Effect sizes identified in the statistical analysis in Objective 2 will be combined with longitudinal trajectories of mental health and life chances identified in each of the longitudinal data sources (Table 1) to estimate potential long-term outcomes. Long-term monetary values will be attached to different life chances outcomes where possible. An example would be to estimate the value of higher rates of school completion for wealth accumulation and income through to adulthood. We will draw on published literature, e.g., costs reported in previous economic analyses of CTPs [47], as well as statistical reports relating to CTPs in the six countries, to estimate their administrative costs. The specific time frame for the modelling will depend on data availability. Costs and outcomes beyond 1 year will be discounted and all monetary values will be reported in purchasing power parity adjusted international dollars.

Modelling will also take account of implementation and scale-up costs in line with previous work [51]. We will also vary underlying assumptions using both deterministic and probabilistic sensitivity analysis to reflect uncertainty on both effectiveness estimates and cost distributions. To increase policy relevance, and after engagement with stakeholders (Objective 5) we will also model specific conservative and optimistic scenarios. This could include varying assumptions on uptake rates to reflect themes in qualitative analysis with young people, families and professionals set out in Objective 4. 


\section{Understanding young people's, families' and professionals' experiences (Objective 4)}

We will conduct semi-structured interviews and focus groups with young people, families and professionals who use or deliver CTPs in the three countries in which our partners are based (Brazil, Colombia and South Africa). The aim of this qualitative research is to elicit information about:

(i) Young people's experiences and meaning of poverty and mental health in these diverse cultures and settings;

(ii) Personal experiences of being involved in the CTP,

(iii) Implementation barriers and facilitators of current programmes; and

(iv) Ideas for future combined CTP and mental health interventions.

The interviews will allow us to gain an in-depth understanding of young people's experiences with CTPs, how they experience mental health and poverty more generally, and how they view their future, whereas in focus groups we seek to get an understanding of the family and community context in which programmes operate. We will elicit views from young people, families and professionals about the local context and about how programmes operate, the role of programme features and how programmes can be improved to better support young people.

We plan to conduct between 15 and 20 interviews and 3 and 4 focus groups in each of the 3 countries. Sampling and recruitment strategies for interviews and focus group will be tailored to the country setting. Partners will build rapport with the community and potential participants beforehand, through community visits and meetings utilising relationships with community organisations, youth groups and nongovernment organisations.

For the interviews, we will invite young people who are past or current users of CTPs, and who received or applied for the cash transfer themselves or who received this via their parents. For the focus groups, we will recruit parents who receive cash transfers, practitioners involved in the delivery of programmes and youth leaders from youth organisations.

Focus groups and interviews will be conducted in the local language, audio-recorded, transcribed and translated into English. First, country-specific analysis will be conducted using the complete data (in the mother language where possible). Next, data (in English) will be harmonised across countries by identifying commonalities. We will apply a constant comparative approach towards the coding $[48,52]$, thus allowing for repeated explorations and reflections with colleagues across countries. Data will be analysed primarily using inductive methods in the form of a framework approach to thematic analysis.

Details on how data for interviews and focus groups will be gathered and analysed following COREQ recommended standards are presented in online resource 1 [53].

\section{Engaging stakeholders and young people (Objective 5)}

A key element of CHANCES-6 is to work in partnership with policy makers and influencers, and other national or local stakeholders. This includes various representatives in governmental and non-governmental organisations (NGOs) who have responsibilities for health and welfare funding, planning and delivery. We will organise highlevel policy workshops in each of the countries where our partners are based (i.e., Brazil, Colombia and South Africa), one in the first and one in the last year of the project. In the first round of stakeholder workshops, we will raise awareness of the research aims, seek feedback on methods and approach, and understand interests and capacities in utilising and implementing findings from the research. In addition, we will gather information that will help us understand implementation barriers and facilitators of current programmes, and opportunities for combined provision of CTPs and mental health programmes. The main aim of the second stakeholder workshop will be to discuss implications of the CHANCES- 6 findings for policies and programme development, implementation and evaluation. We will plan activities to stay engaged with stakeholders between workshops and identify new stakeholders throughout the project. Partners in each of the countries will facilitate an ongoing dialogue with stakeholders, so we can incorporate their feedback as the research develops based, for example, on policy changes (including in relation to COVID-19), and in the interpretation and presentation of findings.

Additionally, we will develop and use various (social) media channels, outputs and tools to create opportunities for engaging with stakeholders and influence policies in all six countries of the project and beyond. Information and updates on the project, including research findings as they become available during the project, will be provided on the project website (https://www.lse.ac.uk/cpec/chanc es-6). We will also engage with representatives from international development agencies such as the World Bank, World Health Organisation and UNICEF and with relevant international communities.

Our ultimate beneficiaries are young people living in poverty. Overall, we plan to work with young people throughout the project, by engaging with youth leaders 
and representatives of organisations which advocate for the rights of young people, locally or nationally. The approach towards engaging with youth will be contextspecific, and build on existing partnerships. Young people will be invited to become involved in telling their stories through social media, and by participating in a short films. Young people will become involved in the project, for example in the roles of advisors, advocates, and research staff. This will include involving students from universities, and involving youth in the interpretation of findings of the research.

\section{Discussion}

CHANCES-6 is a multi-disciplinary, multi-site study, which spans six Latin American and African countries. Innovative data collection and analyses-combined with stakeholder engagement-will generate critical knowledge to inform policies and programme designs that consider young people's mental health when seeking to optimise investment into CTPs. The ultimate aim of this project is to understand how to break the cycle of poverty and mental illness during adolescence to improve young people's future life chances.

Investments into mental health-both in total as well as in proportion to total health expenditure-are very small in LMICs and treatment is available to very few people. CTPs on the other hand are available and reach a substantial proportion of the population. In the global mental health field, a considerable amount of research effort has gone into designing and evaluating treatment interventions in the past $10-15$ years, whereas much less research has been concerned with addressing the social determinants of mental ill health [33]. CHANCES-6 is an opportunity to understand how widely implemented interventions such as cash transfer programmes influence mental health and to develop a more integrated approach to addressing mental health and its social determinants.

There is growing interest among international development agencies and governments in LMICs in understanding the role of poor mental health in maintaining poverty cycles [54]. In this context, CHANCES-6 is particularly salient, for a number of reasons. Firstly, we will generate knowledge on the role of mental health as a mediator and moderator for future life chances of young people living in poverty, and on the causal relationships between poverty and mental health in this population. This addresses an important gap in the evidence as most studies in this area have been descriptive and cross-sectional [40]. Secondly, we will contribute to the emerging evidence on the impact of CTPs on young people's mental health, and the features of programmes that influence mental health. Thirdly, we will generate knowledge on the role of mental health interventions or support in augmenting the impact of CTPs on life chances. Findings from the economic analyses will provide policy stakeholders with the knowledge of the value of CTPs, and whether including access to mental health support as part of such programmes is likely to increase their economic value. Fourthly, we will generate knowledge about the feasibility, opportunities and barriers in relation to how programmes might be best delivered to improve young peoples' mental health and life chances. Finally, CHANCES-6 will generate methodological advances for pooling data from diverse longitudinal data sources to estimate mental health and socio-economic effects that are locally relevant and internationally comparable.

Supplementary Information The online version contains supplementary material available at https://doi.org/10.1007/s00127-021-02043-7.

Funding This study is supported by the UKRI's Global Challenges Research Fund (Grant number ES/S001050/1). The support of the Economic and Social Research Council is gratefully acknowledged. A. Matijasevich receives support from the National Council for Scientific and Technological Development (CNPq), Brazil.

Data availability The data sources for the quantitative analysis are secondary sources, which are already publicly available. For the qualitative data analysis, data are not fully shareable as some of the will contain identifiable information. However, findings from the analysis will be published together with details on the research methods and tools.

Code availability Not applicable.

\section{Compliance with ethical standards}

Conflict of interest On behalf of all authors, the corresponding author states that there is no conflict of interest.

Ethical approval Ethical approval was given by the appropriate ethics committees in accordance with the 1964 Declaration of Helsinki. This includes ethical approval by the Research Ethics Committee at the London School of Economics and Political Science (REC ref. 997). New data collection in Brazil, Colombia and South Africa had approval or is currently seeking approval from local ethical committees. South African ethics approval was obtained from the University of Cape Town Health Sciences Faculty Human Research Ethics Committee (HREC Ref: 396/2019). Brazilian ethics approval was obtained on July 10th 2019 from the National Ethics Committee (CONEP), CAEE: 06777318.2.0000.0084. Colombian ethical approval was granted by the Universidad de los Andes Ethics Committee (Ref: 02376-2019). Ethics approval for secondary analysis of quantitative data conducted at King's College London was obtained from King's College London Research ethics office (LRS-19/20-15050).

Consent to participate Only persons who provide informed consent will be included in the study.

Consent for publication All authors consent to the publication of the manuscript in Social Psychiatry and Psychiatric Epidemiology. 
Open Access This article is licensed under a Creative Commons Attribution 4.0 International License, which permits use, sharing, adaptation, distribution and reproduction in any medium or format, as long as you give appropriate credit to the original author(s) and the source, provide a link to the Creative Commons licence, and indicate if changes were made. The images or other third party material in this article are included in the article's Creative Commons licence, unless indicated otherwise in a credit line to the material. If material is not included in the article's Creative Commons licence and your intended use is not permitted by statutory regulation or exceeds the permitted use, you will need to obtain permission directly from the copyright holder. To view a copy of this licence, visit http://creativecommons.org/licenses/by/4.0/.

\section{References}

1. UNFPA (2014) State of world population 2014. United Nations population fund. https://www.unfpa.org/swop-2014. Accessed 13 July 2021

2. United Nations (2017) World Population Prospects (2017) UN department for economic and social affairs (UN DESA). Population Division, New York

3. UNICEF (2016) Ending extreme poverty: a focus on children. UNICEF and the World Bank Group. https://www.unicef.org/ publications/index_92826.html. Accessed 13 July 2021

4. Goodman A, Joyce R, Smith JP (2011) The long shadow cast by childhood physical and mental problems on adult life. Proc Natl Acad Sci 108(15):6032-6037. https://doi.org/10.1073/pnas.10169 70108

5. Richard R, Abbot R (2009) Childhood mental health and life chances in post-war Britain. Insights from three national birth cohort studies, The Smith Institute Microsoft Word - life chances full report.doc (smith-institute.org.uk). Accessed 13 July 2021

6. Duncan GJ, Yeung WJ, Brooks-Gunn J, Smith JR (1998) How much does childhood poverty affect the life chances of children? Am Sociol Rev 63(3):406-423. https://doi.org/10.2307/2657556

7. Wright RA (1980) RALF DAHRENDORF. Life chances: approaches to social and political theory Pp ix, 181. Chicago: the University of Chicago Press 1980. \$15.00. Ann Am Acad Polit Soc Sci 451(1):193-194. https://doi.org/10.1177/0002716280 45100150

8. Ludwig J, Miller DL (2007) Does head start improve children's life chances? Evidence from a regression discontinuity design. Q J Econ 122(1):159-208. https://doi.org/10.1162/qjec.122.1.159

9. Stewart K, Lupton R (2015) Social mobility under the coalition government: have the life chances of the poorest children improved? I British Politics and Policy at LSE. Accessed 13 July 2021

10. Lund C, Breen A, Flisher AJ, Kakuma R, Corrigall J, Joska JA, Swartz L, Patel V (2010) Poverty and common mental disorders in low and middle income countries: a systematic review. Soc Sci Med (1982) 71(3):517-528. https://doi.org/10.1016/j.socscimed. 2010.04.027

11. Dohrenwend BP, Levav I, Shrout PE, Schwartz S, Naveh G, Link BG, Skodol AE, Stueve A (1992) Socioeconomic status and psychiatric disorders: the causation-selection issue. Science 255(5047):946-952

12. Flisher AJ, Lund C, Funk M, Banda M, Bhana A, Doku V, Drew N, Kigozi FN, Knapp M, Omar M, Petersen I, Green A (2007) Mental health policy development and implementation in four African countries. J Health Psychol 12(3):505-516. https://doi. org/10.1177/1359105307076237

13. Lund C, Cois A (2018) Simultaneous social causation and social drift: longitudinal analysis of depression and poverty in South
Africa. J Affect Disord 229:396-402. https://doi.org/10.1016/j. jad.2017.12.050

14. Alkire S, Santos ME (2013) A multidimensional approach: poverty measurement and beyond. Soc Indic Res 112(2):239-257. https://doi.org/10.1007/s11205-013-0257-3

15. Atkinson A (2003) Multidimensional deprivation: contrasting social welfare and counting approaches. J Econ Inequal 1(1):5165. https://doi.org/10.1023/A:1023903525276

16. Baird SdH, Jocobus; Ozler, Berk (2011) Income shocks and adolescent mental health. Policy research working paper. The world bank development research group, poverty and inequality team, Washington D.C. World Bank Document. Accessed 13 July 2021

17. Patel V, Flisher AJ, Hetrick S, McGorry P (2007) Mental health of young people: a global public-health challenge. Lancet 369(9569):1302-1313. https://doi.org/10.1016/S0140-6736(07) 60368-7

18. Patel V, Saxena S, Lund C, Thornicroft G, Baingana F, Bolton P, Chisholm D, Collins PY, Cooper JL, Eaton J, Herrman H, Herzallah MM, Huang Y, Jordans MJD, Kleinman A, Medina-Mora ME, Morgan E, Niaz U, Omigbodun O, Prince M, Rahman A, Saraceno B, Sarkar BK, De Silva M, Singh I, Stein DJ, Sunkel C, Unützer J (2018) The lancet commission on global mental health and sustainable development. Lancet 392(10157):1553-1598. https://doi. org/10.1016/S0140-6736(18)31612-X

19. Global Burden of Disease Study 2017 Results (2017) http:// vizhub.healthdata.org/gbd-compare/. Accessed 13 July 2021

20. Kieling C, Baker-Henningham H, Belfer M, Conti G, Ertem I, Omigbodun O, Rohde LA, Srinath S, Ulkuer N, Rahman A (2011) Child and adolescent mental health worldwide: evidence for action. Lancet 378(9801):1515-1525. https://doi.org/10.1016/ S0140-6736(11)60827-1

21. Reiss F (2013) Socioeconomic inequalities and mental health problems in children and adolescents: a systematic review. Soc Sci Med 90:24-31. https://doi.org/10.1016/j.socscimed.2013.04. 026

22. Costello EJ, Erkanli A, Copeland W, Angold A (2010) Association of family income supplements in adolescence with development of psychiatric and substance use disorders in adulthood among an American Indian population. JAMA 303(19):19541960. https://doi.org/10.1001/jama.2010.621

23. Palmer GN, Jenny, Carr, Jane, Kenway, Peter (2003) Monitoring poverty and social exclusion 2003. Joseph Rowntree foundation, York, United Kingdom

24. Beardslee WR, Chien PL, Bell CC (2011) Prevention of mental disorders, substance abuse, and problem behaviors: a developmental perspective. Psychiatric Serv (Wash DC) 62(3):247-254. https://doi.org/10.1176/ps.62.3.pss6203_0247

25. Knapp M, Evans-Lacko S (2015) Health economics. Rutter's Child Adolesc Psychiatry. https://doi.org/10.1002/9781118381 953.ch 18

26. Angeles G, de Hoop J, Handa S, Kilburn K, Milazzo A, Peterman A (2019) Government of Malawi's unconditional cash transfer improves youth mental health. Soc Sci Med 225:108 119. https://doi.org/10.1016/j.socscimed.2019.01.037

27. Lund C, De Silva M, Plagerson S, Cooper S, Chisholm D, Das J, Knapp M, Patel V (2011) Poverty and mental disorders: breaking the cycle in low-income and middle-income countries. Lancet 378(9801):1502-1514. https://doi.org/10.1016/S01406736(11)60754-X

28. Barry MM, Clarke AM, Jenkins R, Patel V (2013) A systematic review of the effectiveness of mental health promotion interventions for young people in low and middle income countries. BMC Public Health 13(1):835. https://doi.org/10.1186/ 1471-2458-13-835 
29. Patel V, Kleinman A (2003) Poverty and common mental disorders in developing countries. Bull World Health Organ 81(8):609-615

30. Thirthalli J, Venkatesh BK, Kishorekumar KV, Arunachala U, Venkatasubramanian G, Subbakrishna DK, Gangadhar BN (2009) Prospective comparison of course of disability in antipsychotictreated and untreated schizophrenia patients. Acta Psychiatr Scand 119(3):209-217. https://doi.org/10.1111/j.1600-0447.2008. 01299.x

31. Lawal RA, Adelekan ML, Ohaeri JU, Orija OB (1998) Rehabilitation of heroin and cocaine abusers managed in a Nigerian psychiatric hospital. East Afr Med J 75(2):107-112

32. Skeen S, Laurenzi CA, Gordon SL, du Toit S, Tomlinson M, Dua T, Fleischmann A, Kohl K, Ross D, Servili C, Brand AS, Dowdall N, Lund C, van der Westhuizen C, Carvajal-Aguirre L, Eriksson de Carvalho C, Melendez-Torres GJ (2019) Adolescent mental health program components and behavior risk reduction: a metaanalysis. Pediatrics 144:2. https://doi.org/10.1542/peds.2018-3488

33. Burgess RA, Jain S, Petersen I, Lund C (2019) Social interventions: a new era for global mental health? Lancet Psychiatry. https://doi.org/10.1016/s2215-0366(19)30397-9

34. Lund C, Brooke-Sumner C, Baingana F, Baron EC, Breuer E, Chandra P, Haushofer J, Herrman H, Jordans M, Kieling C, Medina-Mora ME, Morgan E, Omigbodun O, Tol W, Patel V, Saxena S (2018) Social determinants of mental disorders and the sustainable development goals: a systematic review of reviews. Lancet Psychiatry 5(4):357-369. https://doi.org/10.1016/s22150366(18)30060-9

35. Bauer A, Garman E, McDaid D, Pabon MA, Hessel P, Díaz Y, Baltra RA, Lund C, Malvasi P, Matijasevich A, Park A-L, Paula CS, Ziebold C, Zimmerman A, Evans-Lacko S (2021) Integrating Youth Mental Health into Cash Transfer Programmes in response to the COVID-19 Crisis in Low- and Middle-income Countries. Lancet Psychiatry 8(4):340-346. https://doi.org/10.1016/s22150366(20)30382-5

36. Alves FJO, Machado DB, Barreto ML (2019) Effect of the Brazilian cash transfer programme on suicide rates: a longitudinal analysis of the Brazilian municipalities. Soc Psychiatry Psychiatr Epidemiol 54(5):599-606. https://doi.org/10.1007/ s00127-018-1627-6

37. Christian C, Roth, C (2016) Can Cash Transfers Prevent Suicides? Experimental Evidence From Indonesia. https://www.aeaweb.org/ conference/2017/preliminary/paper/5Dt2Kkft. Accessed 13 July 2021

38. Christian C, Hensel L, Roth C (2019) Income shocks and suicides: causal evidence from Indonesia. Rev Econ Statis 101(5):905-920. https://doi.org/10.1162/rest_a_00777

39. Kilburn K, Thirumurthy H, Halpern CT, Pettifor A, Handa S (2016) Effects of a large-scale unconditional cash transfer program on mental health outcomes of young people in Kenya. $J$ Adolesc Health Off Publ Soc Adolesc Med 58(2):223-229. https:// doi.org/10.1016/j.jadohealth.2015.09.023

40. Baird S, Ferreira FHG, Özler B, Woolcock M (2014) Conditional, unconditional and everything in between: a systematic review of the effects of cash transfer programmes on schooling outcomes. J Develop Effective 6(1):1-43. https://doi.org/10.1080/19439342. 2014.890362

41. Samuels F, Stavropoulou M (2016) 'Being able to breathe again': the effects of cash transfer programmes on psychosocial wellbeing. J Develop Stud 52(8):1099-1114. https://doi.org/10.1080/ 00220388.2015 .1134773

42. Eyal K (2016) Follow the child: the effect of an unconditional cash transfer on adolescent human capital and mental health. University of Cape Town, Cape Town, South Africa

43. Attah R, Barca V, Kardan A, MacAuslan I, Merttens F, Pellerano L (2016) Can social protection affect psychosocial wellbeing and why does this matter? Lessons from cash transfers in Sub-Saharan Africa. J Develop Stud 52(8):1115-1131. https://doi.org/10.1080/ 00220388.2015.1134777

44. Beegle K, Coudouel A, Monsalve Montiel E (2018) Realizing the Full Potential of Social Safety Nets in Africa. Africa Development Forum. Washington, DC: World Bank. https://openknowledge. worldbank.org/handle/10986/29789. Accessed 13 July 2021

45. Baird S, McIntosh C, Özler B (2011) Cash or condition? Evidence from a cash transfer experiment *. Q J Econ 126(4):1709-1753. https://doi.org/10.1093/qje/qjr032

46. Prosperidad Social DPS (2017) Informe de la Evaluación de Impacto del Programa Jóvenes en Acción. http://centrodedocumen tacion.prosperidadsocial.gov.co/Documentos\%202019/JeA/Evalu aciones/Evaluacio\%CC\%81n\%20de\%20Impacto\%20del\%20Pro grama $\% 20 \mathrm{Jo} \% \mathrm{CC} \% 81$ venes\%20en $\% 20$ Accio\%CC\%81n-Resum en\%20ejecutivo\%20-\%20Dic\%202017.pdf. Accessed 13 July 2021

47. García S, Saavedra JE (2017) Educational impacts and costeffectiveness of conditional cash transfer programs in developing countries: a meta-analysis. Rev Edu Res 87(5):921-965. https:// doi.org/10.3102/0034654317723008

48. Creswell JW (2014) Research design: qualitative, quantitative, and mixed methods approaches, 4th edn. SAGE Publications, California

49. Dunning T (2012) Natural experiments in the social sciences: a design-based approach. Cambridge University Press, Cambridge, Strategies for Social Inquiry. https://doi.org/10.1017/CBO97 81139084444

50. VanderWeele TJ (2015) Explanation in causal inference: methods for mediation and interaction. Oxford University Press, New York

51. Chisholm D, Heslin M, Docrat S, Nanda S, Shidhaye R, Upadhaya N, Jordans M, Abdulmalik J, Olayiwola S, Gureje O, Kizza D, Mugisha J, Kigozi F, Hanlon C, Adugna M, Sanders R, Pretorius C, Thornicroft G, Lund C (2017) Scaling-up services for psychosis, depression and epilepsy in sub-Saharan Africa and South Asia: development and application of a mental health systems planning tool (OneHealth). Epidemiol Psychiatric Sci 26(3):234244. https://doi.org/10.1017/S2045796016000408

52. Glaser BG, Strauss AL (1967) The discovery of grounded theory: Strategies for qualitative research. Aldine, Hawthorne, New York

53. COREQ (Consolidated Criteria for Reporting Qualitative Studies) (2014) In Guidelines for reporting health research. User's Manual. https://doi.org/10.1002/9781118715598.ch21

54. World Bank (2015) Mind, Society and Behavior: World Development Report World Bank Group Washington DC. World Development Report 2015: Mind, Society, and Behavior (worldbank.org). Accessed 13 July 2021

55. Fiszbein A, Schady N (2009) Conditional cash transfers. World Bank Group, Washington D.C, World Bank Policy Research Report

56. Soares S (2012) Bolsa família, its design, its impacts and possibilities for the future. Working papers 89. International policy centre for inclusive growth. print capa wp 89.pmd (ipcig.org). Accessed 13 July 2021

57. Ministério da Cidadania (2019) O que é o bolsa família. Ministério da Cidadania, Secretaria Especial do Desenvolvimento Social

58. Seekings J (2007) Deserving individuals and groups: justifying the shape of South Africa's welfare state. University of Cape Town, Cape Town, Centre for Social Science Research

59. NIDS (2019) National Income Dynamics Study (2008-2019). University of Cape Town. http://www.nids.uct.ac.za/. Accessed 13 July 2021

60. Blattman CJ, Julian C.; Sheridan, Margaret (2016) Reducing crime and violence: experimental evidence on adult noncognitive investments in Liberia. Policy research working paper. world bank group, development economics vice presidency, development 
policy department, Washington D.C. World Bank Document. Accessed 13 July 2021

61. World Bank Open Data (2019) World Bank. https://data.world bank.org/. Accessed 06 April 2020

62. WHO (2017) Mental Health ATLAS 2017. World Health Organization. https://www.who.int/mental_health/evidence/atlas/mental_ health_atlas_2017/en/. Accessed 13 July 2021

63. Docrat S, Besada D, Cleary S, Daviaud E, Lund C (2019) Mental health system costs, resources and constraints in South Africa: a national survey. Health Policy Plan 34(9):706-719. https://doi. org/10.1093/heapol/czz085
64. Azzopardi PS, Hearps SJC, Francis KL, Kennedy EC, Mokdad AH, Kassebaum NJ, Lim S, Irvine CMS, Vos T, Brown AD, Dogra S, Kinner SA, Kaoma NS, Naguib M, Reavley NJ, Requejo J, Santelli JS, Sawyer SM, Skirbekk V, Temmerman M, Tewhaiti-Smith J, Ward JL, Viner RM, Patton GC (2019) Progress in adolescent health and wellbeing: tracking 12 headline indicators for 195 countries and territories, 1990-2016. Lancet 393(10176):1101-1118. https://doi.org/10.1016/S0140-6736(18) 32427-9 